\title{
Status Analysis and Countermeasures of Human Resource Panning in Small and Medium-sized Enterprises
}

\author{
Meng Zhai ${ }^{1, ~ a, ~}{ }^{*}, \mathrm{Pu} \mathrm{Li}^{1, \mathrm{c}}$, and Chengcheng $\mathrm{Li}^{1, \mathrm{~b}}$ \\ ${ }^{1}$ School of Management Science and Engineering, Shandong Normal University, Ji'nan 250014, China \\ aliufm69@163.com, b1402045013@qq.com, '1141187104@qq.com \\ *corresponding author
}

Keywords: List the, keywords covered, in your paper.

\begin{abstract}
Human resources planning is the primary link and important component of human resource management, which is the leading and strategic, and plays a very important role in achieving the overall development strategy of enterprises. Practical human resources planning can optimize the enterprise management system, achieve corporate strategic objectives and ensure that enterprises calmly deal with external complex and volatile competitive environment. There are still many shortcomings and insufficient development, restricting the development of enterprises in the current SME human resources planning, the development is not sufficient. This paper analyzes the current situation of human resource planning of SMES, identifies the problems, finds out the reasons and proposed countermeasures.
\end{abstract}

\section{Introduction}

Under the condition of deepening the marketization of China's economy, the small and medium-sized enterprises (SMES), as the most dynamic subject in the market economy, have many favorable conditions for their growth and development, including strong adaptability to environmental change, wide areas involved and strong liquidity, which play an irreplaceable role for the development of regional economy, improve employment rate, scientific and technological innovation, stable fiscal revenue, gradually becoming the major force in social production. But in the economic globalization competition, relying on strong economic strength and a wide range of brand awareness some international enterprises settle in the Chinese market and compete to attract talents. While the domestic SMES still exist disadvantages such as high operating costs, weak ability to resist risks, poor scale efficiency and so on, and their popularity and resources are in a weak position. In addition, the development of human resources management of smallest and medium-sized enterprises in China is slow, the concept and method of human resource management are backward, the staff performance appraisal system is not perfect; diversified recruitment channels are lacking, the introduction of talents is insufficient; training the mechanism is not perfect and so on. Although a few enterprises aware of the importance of human resources management and carry out the reform, they ignore the particularity of SMEs, the effect is not obvious.

In the era of people-oriented, high-quality human resources is the guarantee of long-term development of enterprises. The SMEs should strengthen the emphasis on human resources planning, scientifically develop the plan and ensure the effective implementation, optimize the allocation of human resources, in order to meet the long-term human resources needs, improve economic efficiency.

\section{Overview of Human Resource Planning}

\subsection{Human Resource Planning}

Human resource planning is the process to scientifically predict and analyze the organization's 
human resource demand and supply according to the organization's development strategy, objectives and changes in the internal and external environment of the organization, and develop the necessary management policies and measures to ensure that the organization obtains the required human resources at the required time and position.

\subsection{The general process of human resource planning}

The process of human resource planning can generally be divided into several steps: organizational goals and strategies - collect relevant information - human resource demand forecast human resource supply forecast - determine the net demand of human resources - prepare the human resource planning - - implementing human resource planning - human resource planning evaluation human resource planning feedback and revision.

\section{Problems in Human Resource Planning of Small and Medium - sized Enterprises}

\subsection{Human resources planning and enterprise development strategy cannot be matched}

At this stage, the focus of SMEs development is to obtain economic benefits, expand the scale of operation, and expand to different commercial areas. Due to lack of management experience, only want to expand the scale, lack of planning and understanding of all aspects of the new field, the decision-makers cannot clearly understand the enterprise development strategy. Especially in the development of $\mathrm{R} \& \mathrm{D}$, marketing, after-sales service and other processes management, which are not well thought out. In addition, for the new project, the configuration of personnel and the establishment of post are not mature enough. Therefore, in the planning of human resources fails to form a consistent idea, cannot determine the management objectives.

\subsection{The recruitment and use of employees exist of a great deal of randomness}

The recruitment and use of employees in many small and medium-sized enterprises are nonstandard and have strong subjectivity and lack of overall planning. Recruitment is not well prepared and recruitment plans are difficult to implement. The ignorance of the kind of talent that enterprises need, the requirements of the vacant posts and clear job description cause that the recruitment departments do not to know how many people to recruit, recruit what level of talent and is ignored to the job competency of employees. In the absence of talent, the human resources department is engaged in a hasty recruitment, mainly in order to cope with the temporary needs of market changes, with great randomness in this way, it is easy to produce loopholes in the recruitment process, reduce the management and production efficiency of enterprise development, waste resources and affect the image of enterprises in the minds of job seekers.

\subsection{Attracting and retaining key talent for enterprise development are difficult}

Compared with other large enterprises, small and medium-sized enterprises have the disadvantages of high turnover rate and strong employee turnover. A variety of factors contribute to this phenomenon. Some employees in small and medium-sized enterprises have low professional integrity and low corporate loyalty. The lack of scientific nature in human resources planning, good corporate culture and employees' identity and adscription to enterprises cause a great loss of key talent. Simple improvement of wages cannot solve the problem, but to implement more scientific and deeper human resources planning and meet the realization of employee self-worth, which also help employees to develop personal career planning according to corporate human resources planning.

\section{Reasons of problems in human resource planning for SMEs}

\subsection{Lack of understanding of human resource planning}

Most of the SMEs focus on economic interests, attach great importance to technology and capital, and do not attach importance to the development of human resources in the enterprise. The 
management of the enterprise will also focus on the business and financial departments, and pay no attention to the human resources department. The establishment of human resources department only do a simple file management, recruit employees, do not carry out human resources development and other work. And human resources planning is also not carried out. Human resources management work lacks systematic and mature system support, and development lags far behind the business department.

\subsection{Lack of specialized talent}

The work of human resources is very unique, the professional knowledge, learning ability and management ability of relevant practitioners have higher requirements, who also need to master the relevant theoretical knowledge and have a good working attitude. At present, in many small and medium enterprises, human resource management functions by administrative organs, and SMEs do not set up the human department.

\subsection{The uncertainty and fuzziness of enterprise development strategy}

Human resource planning is the foundation of the management of small and medium-sized enterprises, and it is of great significance to small and medium-sized enterprises. The premise of human resource planning is the clear enterprise strategy, the definite goal is the principle of planning formulation, then specific supporting plans can be formulated, such as staff supply and demand plan, performance plan and so on. However, the majority of small and medium-sized enterprises do not have a clear development strategy, especially in the period of rapid expansion, often involve in several business areas. It is difficult to determine a clear strategic direction to develop, which led to the development of human resources planning is no clear direction. And it will be impossible to have a clear plan.

\section{Solutions to the Problems of Human Resource Planning in Small and Medium - sized Enterprises}

\subsection{Develop different human resources planning at each stage of development}

The operation and development of an enterprise is a continuous process and has its own development cycle. Integrated the view of management at home and abroad, the typical enterprise generally goes through four stages, including the founding period, the development period, the mature period and the decline period. Enterprises have their own problems in different stages, and should adopt different human resources planning measures.

\subsection{Strengthen the construction of human resources management team}

Small and medium-sized enterprises must cultivate high-quality, strong and professional human resources management team, and actively carry out targeted vocational training; improve the status of low quality of existing employees, strengthen staff's recognition and learning of human resources management, and organize the on-the-job training among relevant staff; pure human resources management team from the source through external recruitment hiring high-quality human resources management professionals, and make new employees drive the old staff learning.

\subsection{Optimize recruitment mechanism and enhance the standardization of human resource planning}

In order to attract and retain talent and reduce staff turnover, small and medium-sized enterprises must establish a standardized and scientific recruitment mechanism, and strive to create a fair and just good applicant environment. Enterprises should do a detailed understanding of the job description and personnel quality requirements of the recruitment position, and develop a scientific and rational work instructions, standardize recruitment process, make people have ability to work and get a reasonable placement, and make the best use of people. 


\subsection{Construct the external support system of human resource planning for SMEs}

Compared to large enterprises, small and medium-sized enterprises are small with limited strength. In order to promote the development of human resources, small and medium-sized enterprises can help to improve the human resources planning through the construction of the external support system of human resources planning.

\section{Conclusions}

With the continuous development and increasing vitality, small and medium-sized enterprises has become an important component of the market economy. For the sustainable development of China's economy and the enhancement of China's economic strength, we should pay more attention to the development of small and medium-sized enterprises and increase their support for small and medium-sized enterprises. In view of the shortcomings of the human resources planning of small and medium-sized enterprises, we should comprehensively analyze the various causes of the problems, formulate scientific and reasonable countermeasures, improve the professional quality of human resource managers, do well in the recruitment and training, attract high-quality talents, construct human resources management system to help small and medium-sized enterprises to overcome difficulties and get rid of the trouble. It is believed that the good development of human resources will help SMEs break through the bottleneck and achieve great leap forward progress.

\section{Acknowledgement}

This work was supported in part by the National Natural Science Foundation of China (No. 61170038, 61472231, 71701115), the National Social Science Foundation of China (No. 14BTQ049), the Shandong Natural Science Foundation(ZR2017MF058), and Special project for Internet development of social science planning special program of Shandong province(17CHLJ23).

\section{References}

[1] Han Yaguang. Research on human resource planning of small and medium-sized enterprises in guizhou province. Economic perspective (bottom).2011.10

[2] Li-na qu. Research on human resource management of small and medium-sized enterprises in jilin province. Northeast Normal University.2007.4

[3] Jing Zhang. Research on human resource planning of small and medium-sized enterprises. Although the line of sight.2013.8

[4] Wang Daoxun. The present situation and countermeasure of human resource planning in small and medium-sized enterprises. intelligence 2013(14)

[5] Su Qiuyue, The crisis and management of human resource planning in small and medium-sized enterprises. management research.2008.1

[6] Wu hongmei, sun jing. Crisis and treatment of human resource planning in small and medium-sized enterprises. financial community.2010.4

[7] Li Kejia. The impact of human resource planning on smes. Entrepreneur world: the mid-day magazine.2012.9

[8] Li Gaiyan. The problems and countermeasures of human resource planning in small and medium-sized enterprises are discussed. Business Modernization.2012(32)

[9] Aoyang qing. Research on human resource planning of small and medium-sized enterprises in jiangxi province -- take AR company as an example. Economics and management science.2011

[10] Tang ruifang, Zeng yuying. The problems and countermeasures of human resource planning in small and medium-sized enterprises. modern economy.2007.6

[11] Zeng Xia. Discussion on human resource planning and countermeasures of small and medium-sized enterprises. China Collective Economy.2011(13). 